\title{
La Biblioteca Nacional del Perú en la prensa escrita:
}

\section{$1945-2013$}

\author{
Orlando Corzo Cauracurí \\ Universidad Nacional Mayor de San Marcos, Lima, Perú \\ orlandocorzoc@gmail.com
}

DOI: https://doi.org/10.26512/rici.v12.n3.2019.22786

Recebido/Recibido/Received: 2019-02-12

Aceitado/Aceptado/Accepted: 2019-08-20

Resumen: El estudio exploró el tratamiento de informaciones referidas a la Biblioteca Nacional del Perú (BNP) en el periodo comprendido entre 1945 y 2013. En base a una muestra de 517 notas periodísticas, identificó 13 campañas en medios impresos de Lima que tienen como tema a la BNP. Analizó los discursos contenidos y sintetizados en titulares y encabezados periodísticos, identificando términos y expresiones reiterativas que orientan y configuran percepciones y creencias culturales relacionadas a la BNP. Concluye que la campaña del año 2011: "Biblioteca Nacional cierra por robos" es la que ha generado mayor cobertura en medios por la cantidad de noticias y opiniones generadas, duración y permanencia en medios, columnas de opinión y editoriales publicadas.

Palabras claves: Biblioteca Nacional del Perú. Bibliotecas y medios de comunicación. Percepciones sobre bibliotecas.

The National Library of Peru in the written press: 1945 - 2013

Abstract: The study explored the treatment of information related to the National Library of Peru (BNP) in the period between 1945 and 2013. Based on a sample of 517 journalistic notes, it identified 13 campaigns in print media in Lima that have as their theme the BNP. It analyzes the discourses contained and synthesized in news headlines and headlines, identifying reiterative terms and expressions that orient and configure cultural perceptions and beliefs related to the BNP. It is established that the campaign of 2011: "National Library closes for theft" is the one that has generated the most media coverage due to the amount of news and opinions generated, duration and permanence in the media, opinion columns and published editorials.

Keywords: National Library of Peru. Libraries and mass media. Perceptions of libraries.

A Biblioteca Nacional do Peru na imprensa escrita: 1945 - 2013

Resumo: $O$ estudo explorou o tratamento de informações relacionadas à Biblioteca Nacional do Peru (BNP) no período 1945 e 2013. Baseado numa amostra de 517 notas jornalísticas, foram identificadas 13 campanhas na mídia impressa em Lima que têm como tema a BNP. Foram analisados os discursos conteúdos e sintetizados em manchetes, identificando os termos e expressões reiterativas que orientam e configuram percepções e crenças culturais relacionadas à la BNP. Conclui-se que a campanha de 2011: "Biblioteca Nacional fecha por roubo" é foi a que mais gerou cobertura de mídia por causa do número de notícias, e opiniões geradas, duração e permanência na mídia, colunas de opinião e editoriais publicados. Palavras-chave: Biblioteca Nacional del Perú. Bibliotecas e mídias de comunicação. Percepções sobre bibliotecas. 


\section{Introducción}

El estudio surge de la necesidad de conocer y reflexionar sobre la presencia y representación de la Biblioteca Nacional del Perú (BNP) en los medios de comunicación masiva, la formación de opinión pública, percepciones y creencias culturales asociadas a bibliotecas y bibliotecarios.

Para conocer cómo los medios eligen qué publicar, los temas o el conjunto de contenidos que son elegidos para su publicación se recurre a la teoría sobre la Agenda-Setting y cómo la elección de titulares orienta a la opinión pública sobre los temas de mayor relevancia. Según Rodríguez (2000) “Las personas no sólo reciben información a través de los medios sobre determinados temas o asuntos que ocurren en el mundo y son considerados relevantes, también aprenden de ellos la importancia y el énfasis que les deben dar." (RODRÍGUEZ, 2000, p. 19-20)

Para entender, comprender y reconocer cómo se configuran las percepciones de sectores de la ciudadanía con respecto a la BNP, se recurre a la teoría y métodos desarrollados por los estudios críticos del discurso sobre construcción de opiniones y creencias de los públicos lectores de medios impresos. Pardo (2013) propone hacer explícitos los significados que subyacen al discurso y su consecuente resignificación. La resignificación por parte del lector de las noticias y comentarios que los medios publican es constante, pasa por ser aprendida, reproducida, adaptada y recreada. Cuando es compartida por una parte importante del grupo social, esa construcción de la realidad se convierte en una creencia cultural. (PARDO, 2013, p. 194-195).

\section{Revisión de literatura}

A modo de guía bibliográfica, Jorge Córdova (1982), elaboró una extensa bibliografía que incluye una sección de publicaciones periódicas que registra noticias referidas a la biblioteca escolar en diarios y revistas entre 1922 y 1981 . Recientemente, con enfoque de marketing, Estrada y Huamán (2010) tratan del posicionamiento de las bibliotecas universitarias en los medios de comunicación en el periodo comprendido entre los años 2007 y 2009.

El análisis del discurso en los medios de comunicación en el Perú se ha empleado para estudiar conflictos sociales, en particular el conflicto conocido como "baguazo". (MACASSI y SUBAUSTE, 2009; ARRUNÁTEGUI, 2010; ETO, 2010). 


\section{Método}

Las unidades a observar son las notas periodísticas (notas informativas, crónicas, informes, reportajes y entrevistas) publicadas en diarios impresos de Lima.

Periodo a analizar: El periodo a analizar corresponde a la historia reciente de la BNP, desde el año 1945, relacionado a la reconstrucción de la Biblioteca luego del incendio de 1943, hasta el año 2013, posterior a la crisis generada por el robo de libros en la BNP.

Niveles de análisis: El análisis de los datos registrados se hace de manera cuantitativa y cualitativa en los siguientes niveles:

a. Número de notas periodísticas por periodo de años que permite determinar una “campaña" periodística, su tematización y consecuente denominación.

b. Espacio dedicado a la noticia relacionada a la BNP por el medio impreso. Preferentemente se observarán primeras planas, notas editoriales e informes a página completa.

c. El sentido de los mensajes. Analiza los discursos contenidos y sintetizados en titulares y encabezados periodísticos, identifica e interpreta las reiteraciones y sentido connotativo que orientan y configuran percepciones y creencias culturales relacionadas a la BNP.

\section{Resultados}

Se analizan 517 notas periodísticas, las cuales constituyen una muestra representativa de la cobertura brindada a la Biblioteca Nacional del Perú como tema en los diarios: Correo, Diario16, El Comercio, El Peruano, El Popular, Expreso, Gestión, La Crónica, La Primera, La República, Perú21, Trome. Revistas: Caretas, Etiqueta Negra, Oiga, Sí.

\subsection{Resultados cuantitativos}

Los resultados cuantitativos muestran la concentración y cobertura mediática por número de notas periodísticas en periodos anuales (tablas 1 y 2 ). Se determinan "campañas" periodísticas por cantidad de noticias, duración o permanencia en el medio, la cobertura proporcionada a un tema específico; el tamaño de la nota en proporción de página completa, considerando de particular importancia la presencia de portadas y editoriales. 
Tabla 1

La Biblioteca Nacional en medios impresos 1945-2013. Portadas, páginas completas y editoriales

\begin{tabular}{|c|c|c|c|c|}
\hline Año & $\begin{array}{l}\mathbf{N}^{\circ} \\
\text { Notas }\end{array}$ & $\begin{array}{l}\mathbf{N}^{\circ} \\
\text { Portadas }\end{array}$ & $\begin{array}{l}\mathbf{N}^{\circ} \text { páginas } \\
\text { completas }\end{array}$ & $\begin{array}{l}\mathbf{N}^{\circ} \\
\text { Editoriales }\end{array}$ \\
\hline 1945 & 11 & & 1 & \\
\hline 1962 & 1 & & & \\
\hline 1978 & 23 & 6 & 8 & \\
\hline 1979 & 3 & 1 & & 1 \\
\hline 1980 & 12 & 2 & & 2 \\
\hline 1981 & 2 & & 1 & \\
\hline 1986 & 3 & & 1 & \\
\hline 1987 & 6 & & 2 & \\
\hline 1989 & 1 & & 1 & \\
\hline 1990 & 12 & 2 & 2 & \\
\hline 1991 & 37 & 2 & 2 & \\
\hline 1992 & 2 & 1 & 1 & \\
\hline 1993 & 34 & 2 & & \\
\hline 1994 & 17 & & & \\
\hline 1995 & 1 & & & \\
\hline 1996 & 8 & & 2 & \\
\hline 1997 & 10 & & 2 & 1 \\
\hline 1998 & 6 & & 1 & \\
\hline 1999 & 4 & 1 & 2 & \\
\hline 2000 & 2 & 1 & & \\
\hline 2001 & 1 & & & \\
\hline 2002 & 8 & 1 & 2 & \\
\hline 2003 & 21 & 1 & 5 & 2 \\
\hline 2004 & 8 & & & \\
\hline 2005 & 25 & 1 & 1 & \\
\hline 2006 & 43 & 2 & 6 & \\
\hline 2007 & 46 & 2 & 3 & \\
\hline 2008 & 24 & & 1 & 1 \\
\hline 2009 & 28 & 1 & 1 & \\
\hline 2010 & 5 & & & \\
\hline 2011 & 84 & 3 & 5 & 2 \\
\hline 2012 & 17 & & 3 & \\
\hline 2013 & 12 & & 1 & \\
\hline TOTAL & 517 & 29 & 53 & 9 \\
\hline
\end{tabular}

\begin{tabular}{|l|l|}
\hline $\begin{array}{l}\text { Tabla } 2 \\
\text { Cobertura sobre la BNP por medio } \\
\text { impreso 1943-2013 }\end{array}$ \\
\hline Medio impreso & $\begin{array}{l}\text { N }^{\circ} \text { Notas } \\
\text { sobre BNP }\end{array}$ \\
\hline El Comercio & 186 \\
\hline La República & 146 \\
\hline El Peruano & 37 \\
\hline Expreso & 5 \\
\hline Correo & 25 \\
\hline La Crónica & 1 \\
\hline Última Hora & 6 \\
\hline Peru21 & 24 \\
\hline El Popular & 4 \\
\hline Diario16 & 5 \\
\hline La Primera & 22 \\
\hline La Razón & 1 \\
\hline El Sol & 1 \\
\hline Trome & 18 \\
\hline Gestión & 1 \\
\hline Caretas & 30 \\
\hline Oiga & 1 \\
\hline Sí & 1 \\
\hline Somos & 1 \\
\hline Etiqueta Negra & 1 \\
\hline Enfoque Derecho & 1 \\
\hline Total & 517 \\
\hline Fuente y elaboración: Propia \\
\hline & \\
\hline
\end{tabular}




\begin{tabular}{|l|l|}
\hline \multicolumn{1}{|c|}{ Campañas periodísticas en medios impresos de Lima 1945-2012 } \\
\hline Año & Título asignado \\
\hline $\mathbf{1 9 4 5}$ & Festival taurino a beneficio de la Biblioteca Nacional. \\
\hline $\mathbf{1 9 7 8}$ & Biblioteca Nacional en peligro. Creación de Patronato de ayuda a biblioteca. \\
\hline $\mathbf{1 9 8 0}$ & Penurias de la Biblioteca Nacional. \\
\hline $\mathbf{1 9 8 7}$ & Con los libros a otra parte. \\
\hline $\mathbf{1 9 9 1}$ & Biblioteca Nacional declarada en emergencia. \\
\hline $\mathbf{1 9 9 3}$ & Biblioteca Nacional cierra sus puertas. \\
\hline $\mathbf{1 9 9 5 - 9 7 - 9 9}$ & Obras de la Biblioteca Nacional paralizadas. \\
\hline $\mathbf{2 0 0 2}$ & Patrimonio fílmico en riesgo. \\
\hline $\mathbf{2 0 0 3}$ & Un nuevo sol por la Biblioteca Nacional. \\
\hline $\mathbf{2 0 0 6}$ & Inauguración de nuevo local de la Biblioteca Nacional. \\
\hline $\mathbf{2 0 0 7}$ & Devolución de libros por parte de Chile a la Biblioteca Nacional. \\
\hline $\mathbf{2 0 0 9}$ & Trafican con libros de Biblioteca Nacional. \\
\hline $\mathbf{2 0 1 1 - 1 2}$ & Biblioteca Nacional cierra por robos. \\
\hline Fuente y elaboración: Propia \\
\hline
\end{tabular}

\subsubsection{Festival Taurino a beneficio de la Biblioteca Nacional (1945)}

La tragedia del incendio de la Biblioteca el año 1943 obligó a reconstruir infraestructura y adquirir libros para reconstituir la colección bibliográfica de la BNP. Se recibieron valiosos donativos que fueron disminuyendo mientras transcurrían los meses, se establecieron canjes con diversas bibliotecas y, naturalmente, se debía adquirir por compra. El presupuesto de la Biblioteca no era suficiente, se requería de donativos en dinero.

Narra Basadre (1968) en sus memorias como no faltaron quienes criticaron la realización de un festival taurino, considerado "poco intelectual" asociado a las actividades de la Biblioteca. Las iniciativas se enmarcaban en un entorno signado por un "resbaladizo ambiente intelectual de Lima", que busca determinar lo adecuado y correcto.

La organización de la corrida de toros pro-Biblioteca Nacional estuvo a cargo de la Asociación de Artistas Aficionados y "el resultado económico fue mucho más cuantioso que el que hubiera producido una velada literario-musical, que, por otra parte, nadie trató de organizar". (BASADRE, 1968, p. 53)

La campaña publicitaria en el diario El Comercio fue en base a avisos pagados, del 25 de febrero al 4 de marzo, fecha de la corrida. Colaboró Francisco Moncloa F. gerente de Publicidad Tres, empresa encargada de la propaganda de la Temporada Taurina 1945.

La corrida de toros a beneficio de la BNP fue un éxito económico y "social”, el lenguaje empleado en la nota publicada por el diario El Comercio el 5 de marzo así lo expresa:

$Y$ el sol abriose en la arena para que, desde los coches y como imágenes escapadas de la paleta de Romero de Torren, lucieran su gracia y su tronio las mujeres de Lima que brindaron su gentil 
concurso, para el despeje organizado por la Asociación de Artistas Aficionados". ("DE TOROS," 1945)

Fueron varias las actividades de particulares que donaron dinero para la compra de colecciones llegaron a entregar a la Biblioteca casi un millón de soles, además del donativo realizado para la compra de la colección Justo; el festival taurino de 1945 fue de mayor impacto mediático.

\subsubsection{Biblioteca Nacional en peligro. Creación de Patronato de ayuda a biblioteca (1978).}

Entre el 31 de enero y el 19 de febrero de 1978, el diario Correo desarrolló una campaña que llamaba la atención sobre la situación por la que atravesaba la BNP y de apoyo a la creación de un Patronato privado pro-Biblioteca Nacional.

Eran los últimos años del gobierno militar en su segunda fase, con crisis económica, huelgas sindicales y movilizaciones populares de protesta. Se publicaron en total 22 notas periodísticas: 6 titulares de primera plana, 2 editoriales y 8 páginas completas sobre la BNP. Se difunden problemas de seguridad, de colecciones y usuarios. Es notorio que el diario asume en sus editoriales el lenguaje y terminología de los bibliotecarios para exponer las necesidades de la Biblioteca. Correo editorializa el 8 de febrero de 1978:

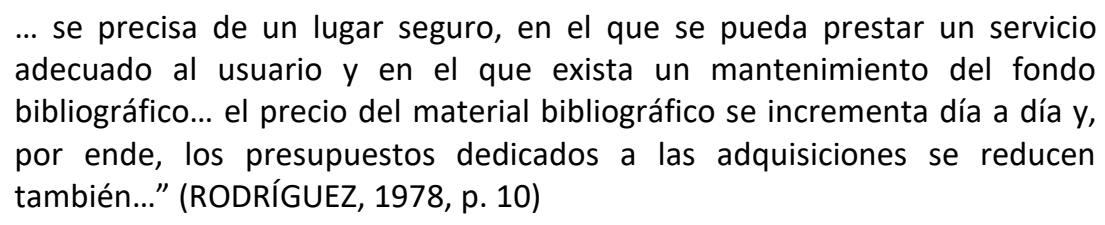

El 31 de enero de 1978 el diario Correo publica: "Biblioteca Nacional en peligro: Está rodeada de orates, mendigos, delincuentes y homosexuales". En páginas interiores, a doble página, la directora de la Biblioteca María Bonilla brinda declaraciones mostradas en una diagramación enmarcada en rojo: "Directora lanza un dramático S.O.S.", "Enfermos mentales destrozan los vidrios a pedradas", "Los jirones Miró Quesada y Ucayali han sido convertidos en letrinas", "No hay vigilancia policial”. ("BIBLIOTECA Nacional en peligro," 1978)

La campaña de creación del Patronato Privado invitaba a bancos y financieras a donar sumas de dinero para la Biblioteca. El 8 de febrero, en portada, Basadre proponía crear un impuesto sobre artículos suntuarios: "El lujo debe dar dinero a la Biblioteca" resumía la entrevista al historiador reconstructor de la BNP. (“EL LUJO debe," 1978)

El éxito de la campaña es relativo, puede ser medido a nivel político, es decir, a nivel de ser visible y de ser reconocido como interlocutor válido; y a nivel operativo, con el incremento de presupuesto. Entre el 9 y 15 de febrero el Ministro de Educación declaró a los medios que el Patronato de la Biblioteca era casi un hecho; se anuncia que se cuenta con 30 millones, faltando 
sólo la elaboración del reglamento para concretar el aporte de las financieras. ("YA HAY treinta," 1978, p. 7)

\subsubsection{El Catálogo Hall}

Tan solo una breve nota menciona que como parte del programa celebratorio del 158 aniversario de la BNP, su directora dio a conocer la edición del catálogo de autores peruanos, una "monumental obra que contiene la reproducción de 90.009 fichas catalográficas en seis tomos que cubren cuatro siglos, desde 1553 hasta 1997, un lapso de 424 años de producción bibliográfica” (“PERÚ es uno,” 1979, p. 11)

La edición del catálogo Hall constituyó, en su momento, la expresión del nivel técnico alcanzado por la BNP comparado con otras bibliotecas de la región, resultado de un proceso de selección por parte de la editorial Hall que culmina en la edición de lo que se consideraba el mayor desarrollo técnico en control de autoridades y descripción bibliográfica de América del Sur y América Central.

Las referencias a las campañas de 1979 y 1980 no estarían completas si no se menciona que las notas de portada y editoriales del diario El Comercio sobre los problemas y la formación de la Sociedad de Amigos de la BNP, corresponden al período como director del diario de Juan José Vega, historiador que por un tiempo cursó estudios en la Escuela Nacional de Bibliotecarios. ("SOCIEDAD de Amigos," 1979, p. 2).

\subsubsection{Penurias de la Biblioteca Nacional (1980).}

Agosto de 1980 corresponde al periodo de transición en que los militares entregan el gobierno a los civiles y se revisan las agendas sobre prioridades. En ese contexto, el diario EI Comercio, como un homenaje al recientemente fallecido Jorge Basadre, inicia una campaña sobre el problema de las bibliotecas.

La editorial de El Comercio del 1 de agosto informa que de 7 millones asignados sólo 2 recibe la Biblioteca Nacional. ("DE 7 millones," 1980, p. 7). El 23 de agosto, en primera plana, El Comercio publica: "Biblioteca no puede comprar más libros: presupuesto mensual es de 54,000 mil soles" y la leyenda que acompaña a la foto de un empleado manipulando libros en mal estado dice: "La Biblioteca Nacional no sólo está desactualizada gravemente. El uso y la acción vandálica de los lectores, ha ocasionado la destrucción o el deterioro irreversible del $20 \%$ de sus libros de lectura corriente" (“BIBLIOTECA no puede," 1980, p.1)

Dos portadas y una editorial en un mes dedicadas al tema de la BNP son muestra de la orientación de colocar en agenda el problema de las bibliotecas. Se recurre a encabezados de notas como "Aguda crisis vive la Biblioteca Nacional al cumplir 159 años", "Bibliobús no funcionó 
el año pasado: no había dinero para comprar repuestos", "Escolares han destruido el 50\% de libros de Biblioteca Piloto", "La Biblioteca Nacional está 30 años desactualizada en ciencias".

\subsubsection{Con los libros a otra parte (1987).}

Juan Mejía Baca fue nombrado Director de la BNP en agosto de 1986. Esencialmente librero y editor, fue convocado para colaborar en una función considerada no política y de amor al libro. Mejía Baca hablaba en los medios al inicio de su gestión que la Biblioteca, sólo con sus filiales, podría convertirse en una gran editorial popular.

La campaña mediática de febrero de 1987 recurrió como principal caja de resonancia a la revista Caretas. Seis meses después de asumir el cargo, se propuso trasladar la BNP a un lugar alejado del bullicio del centro de la ciudad. Caretas agrega a la nota una significativa frase: “Desde que fue nombrado Director de la Biblioteca Nacional, Juan Mejía Baca está empeñado en reflotar la vetusta y caótica institución" ("CON los libros," 1987, p. 57).

Como resultado de la campaña emprendida en febrero de 1987, a cuatro meses de concluir su mandato presidencial, el 28 de marzo de 1990, el presidente Alan García encabezó la ceremonia de colocación de primera piedra de la nueva sede de la BNP. Faltaba una larga lista de trámites legales de afectación del terreno, lo importante del momento era que la prensa registrara la simbólica colocación de la primera piedra de la nueva biblioteca.

En setiembre de 1990, Mejía Baca declaraba al diario La República que desde el mes de marzo se encontraban impagos por falta de dinero los recibos de agua y electricidad, "si no les han cortado el suministro de ambos servicios es gracias a las gestiones amicales que tuvo que hacer" (“BIBLIOTECA Nacional pide," 1990, p. 9).

\subsubsection{Biblioteca Nacional declarada en emergencia (1991).}

El Director de la BNP, José Tamayo Herrera, declaró que la primera actitud a asumir será encomendarse a San Martín de Porres para hacer frente a la cuantiosa deuda con ElectroLima, Sedapal y la Compañía Peruana de Teléfonos. El 26 de diciembre de 1990 la Biblioteca quedó a oscuras hasta el día siguiente. Los empleados de la Biblioteca se movilizaron a nivel de la prensa nacional y la andanada dio resultados. ("BIBLIOTECA Nacional en riesgo" 1991, p. B10)

Tamayo estableció sus prioridades al frente de la BNP, primero, la seguridad ante la amenaza de siniestros; segundo, alcanzar la modernización automatizando; tercero, la Medalla Jorge Basadre, para incentivar por medios éticos, morales y honoríficos la eficiencia del personal, que reconoce mal remunerado, poco motivado y frustrado. (CISNEROS, 1991, p. 3)

El 10 de octubre de 1991, por D.S. 0028-91-ED, se declaró en emergencia a la BNP, por atravesar "un grave problema de índole organizativo-estructural", se formó una Comisión 
revalorizadora presidida por el jefe del Instituto Nacional de Cultura Pedro Gjurinovic. (“UNA comisión," 1991)

Los informes publicados en los diarios fueron sorprendentes: "Biblioteca Nacional no tiene inventario al día", "ninguna dependencia de la Biblioteca conoce el número exacto de ejemplares, ni siquiera en la Dirección de Investigaciones Bibliográficas y Fondos Especiales". "Muchos documentos inéditos como las partituras originales del Himno Nacional, se han archivado en pequeños sobres que hacen más difícil su ubicación" (ZAPATA, 1991, p. a9)

En una significativa nota dedicada a entrevistar a ex directores de la BNP, publicada por El Comercio el 4 de noviembre de 1991, se resumen los males de la Biblioteca. Según Tamayo: falta de autoridad y el poder del sindicato, cortas partidas presupuestales y el desinterés de los gobiernos por la "cenicienta" de las instituciones públicas. Para Pease: la BNP no es tratada como una institución cultural sujeta a normas especiales, debe tener mayor flexibilidad para la adquisición de bienes como para la importación directa de libros; la falta de promoción que ha generado el éxodo masivo de profesionales incrementándose el personal administrativo que no se siente identificado con el quehacer de la BNP. Estuardo Nuñez: la BNP se ha convertido en biblioteca universitaria, escolar y pública. "Ahora los libros son fácilmente sustraídos de los depósitos para ser vendidos a terceras personas sin ningún control”. (“ESTADO nunca," 1991, p. a9)

\subsubsection{Biblioteca Nacional cierra sus puertas (1993)}

"Es increíble que no exista un inventario general de todos los libros, folletos, revistas, periódicos, planos y mapas que guarda en sus salas y depósitos" reza la nota publicada por EI Comercio el 6 de febrero, recoge declaraciones de la jefa institucional Martha Fernández sobre los criterios guías de la reorganización: "se debe cambiar el concepto que se tiene de ella: una institución que atiende masivamente al público". "La idea es que la Biblioteca Nacional se convierta en un centro de investigación que apoye e incentive a las demás bibliotecas del país" (“BIBLIOTECA Nacional necesita total," 1993, p. a8)

La reorganización de la BNP entre 1992 y 1993 tuvo como uno de sus ejes centrales la reducción y cambio de trabajadores de la BNP. Un proceso de reducción de personal planteado en etapas, iniciado con incentivos para retiro voluntario, seguido por evaluaciones, dieron como resultado que de 280 trabajadores en diciembre de 1991 la BNP llegó a contar con sólo 50 trabajadores a marzo de 1993. ("BIBLIOTECA Nacional reabrirá," 1993, p. a12; ALPISTE, 1993, p. 8-9)

Los informes periodísticos presentan encabezados como "Biblioteca Nacional: Hay evidente falta de seguridad", "En 10 años la acidificación convertirá en polvo toda la 
documentación" "Cementerio periodístico", etc. ("HAY evidente," 1993, a7). Se repiten entrevistas a personalidades ligadas a la cultura y ex directores de la BNP. Se recurre a textos de Jorge Basadre referidos a la Biblioteca y a opiniones de exdirectores que expresan su "preocupación por situación de la Biblioteca Nacional”. ("iQUÉ tiempos," 1993, p. c2)

La BNP reabrió sus puertas el 1 de abril de 1993, con 50 trabajadores, en base a estantería abierta y la noticia de reducción presupuestal para la Biblioteca por objeciones del Ministerio de Economía, que aprobó sólo un millón 600 mil soles de los tres millones solicitados. (“REDUCEN partida," 1993, p. a7)

\subsubsection{Obras de la Biblioteca Nacional paralizadas (1994-1999)}

Anuncios y promesas incumplidas, planos y maquetas, tiras y aflojas presupuestales, inicio y abandono de obras. El encabezado del 1 de enero de 1994 de El Comercio, referido al nuevo local de la Biblioteca: "El cuento de nunca acabar" puede resumir el periodo. (CASTILLO, 1994, p. a10)

El diario El Comercio publicaba el abandono mientras que el diario oficial El Peruano publicaba notas optimistas y de proyección al futuro. Mientras El Comercio dispuso la visita regular de reporteros a la Biblioteca para recoger noticias institucionales, El Peruano publicaba entrevistas a las autoridades y notas de prensa oficiales.

Uno de los textos que acompaña la entrevista a la jefa institucional de la BNP, Martha Fernández, en El Peruano de abril de 1996 reza: “Las bibliotecas en el país han alcanzado óptimos niveles de servicio y actualización". (ESCALANTE, 1996, p. a6-a7)

Como parte de los anuncios por el aniversario de la BNP, El Comercio publicó el 1 de agosto de 1997 sobre la implementación de computadoras con acceso a internet. ("CABINAS con acceso," 1997, a17). En marzo de 1998, El Comercio informa que la BNP tiene página web. (“BIBLIOTECA Nacional tiene," 1998, p. c8)

Entre los años 1994-1999 El Comercio mantuvo una campaña de notas e informes periodísticos que llamaban la atención sobre el abandono y necesidad de culminación del nuevo edificio de la BNP. Destacan los informes sobre la demora de la empresa estatal Centromin en entregar el terreno para la BNP (“CENTROMín no entregó," 1994, a6). La falta de presupuesto para culminar tres pisos de nueva sede de Biblioteca Nacional. (“FALTA presupuesto," 1996, a12). La paralización de obras de nuevo local de Biblioteca. ("HACE cuatro meses," 1997, a10). Las cuentas por cobrar de la UNI, encargada de las obras ("LA UNI tiene," 1998, a9). Hasta una portada a todo color que mostraba a la futura biblioteca como cochera de vehículos (FLOR, 1999, p. a1) 
El corolario lo puso el presidente Fujimori, el 10 de junio de 1999, en conferencia de prensa, ante la pregunta de los periodistas sobre la paralización de obras de la BNP afirmó: "No hay fondos para culminar la Biblioteca". ("NO hay fondos," 1999, p. a5). Un día antes una nota de El Comercio mostraba imágenes de maquinaria pesada estacionada con el operario durmiendo y autos estacionados en la zona que debería ser sala de lectura. Fujimori cuestionó la obra sin planificación y sin coordinación con los ministerios de Economía y Educación.

\subsubsection{Patrimonio fílmico en riesgo (2002)}

En el contexto de un gobierno democráticamente elegido se recurre nuevamente al miedo para llamar la atención de los gobernantes sobre la situación de la BNP.

"El patrimonio fílmico del país corre riesgo de perderse: Amenaza de incendio es permanente", el subtítulo es empleado para ampliar y esclarecer, por si no quedaba claro lo que ocurre con las películas de nitrato. ("EL PATRIMONIO," 2002, p. a1). El Director de la Biblioteca, Sinesio López, acude a la prensa al recibir respuestas negativas después de realizar gestiones solicitando al Ministerio del Interior y a la Policía Nacional un local para trasladar las películas de nitrato.

A inicios de setiembre del 2002, en los acostumbrados informes de aniversario de la BNP, Sinesio López anuncia que el Ministro de Economía, Javier Silva Ruete le había comunicado que el presupuesto del año 2003 incluiría los ansiados 11,5 millones de dólares para culminar la construcción del nuevo local de la Biblioteca Nacional. Los trabajos se reanudarían en enero del 2003. Mientras, 70 empleados nunca serán suficientes para atender a 2,000 personas diarias y bibliotecólogos que ganan 900 soles dejarán la biblioteca tentados por instituciones privadas que ofrezcan más. (“MEF dará,” 2002, p. a23)

\subsubsection{Un nuevo sol por la Biblioteca Nacional (2003)}

Se inicia el año 2003 y Patricia Castro de El Comercio pregunta a Sinesio López en una entrevista ilustrada con diagramas y planos de los 5 pisos con los que contaría la nueva sede de la BNP:

¿Cómo logró convencer a las autoridades de reanudar la construcción? - Traté de conseguir un préstamo de 11,5 millones de soles a través de Cofide. Propuse hipotecar el millón de soles anuales que la Biblioteca produce como recursos propios. El Estado lo único que me decía era que me ofrecía garantías y me daba todo su apoyo, pero nada de plata. Al final no se pudo obtener el préstamo. Hasta que el ministro Silva Ruete me llamó a su oficina y me preguntó cuánto dinero necesitaba para comenzar. - ¿Qué hizo al gobierno cambiar de parecer? - Me parece que la presión de la opinión pública. (CASTRO, 2003, p. c23) 
Como ha ocurrido siempre, la BNP recibió dos millones de los once que le fueron ofrecidos para culminar el casco del nuevo edificio. Sinesio López fue obligado a recurrir a la "fórmula histórica" que la Biblioteca siempre ha utilizado para superar carencias: pedir donaciones. Por dos razones, explicaba el Director de la BNP a La República el 14 de agosto del 2003: el gobierno dice no tener recursos y a la élite política parece no interesarle para nada la cultura. "Así lo hizo Palma, mendigó libros después de la guerra con Chile. Así se hizo después del incendio de 1943. Ahora, ante la indolencia del Estado por la Biblioteca Nacional, el mendigo soy yo" (ESCRIBANO, 2003, p. 20)

El 28 de agosto, en un nuevo aniversario de la BNP, El Comercio dedicaba noticia de portada a la campaña. Se esperaba recaudar 9 millones de soles en la colecta de ese día. "Colabore con un sol que no lo hará pobre". "Pobre nuestro patrimonio cultural". ("UN SOL," 2003, p. a1)

La campaña recibió amplio apoyo en la prensa nacional, especialmente el 5 de setiembre en el diario La República, donde Sinesio López era colaborador en la sección de opinión. "iLa Biblioteca Nacional del Perú es de todos, construyámosla juntos!", "Dona un nuevo sol”, "Done un sol y salve a la Biblioteca Nacional del Perú". Se precisaba que era una campaña sostenida y que el 10 de noviembre, "Día de la Biblioteca Escolar", se realizaría la recolección a nivel nacional. (“DONE UN SOL," 2003, p. 26)

Entre el 28 de agosto del 2003 y abril del 2005 se realizaron actividades que tuvieron cobertura en la mayoría de los medios escritos. "Un sol por la Biblioteca Nacional" fue en esencia una campaña de sensibilización de la opinión pública y de las autoridades sobre la necesidad de concluir el nuevo local de la BNP.

\subsubsection{Inauguración de la Biblioteca Nacional (2006)}

La nueva sede de la BNP fue inaugurada el 27 de marzo del 2006. El presidente Toledo visitó las obras de construcción a inicios de febrero del 2005 (García, 2005) comprometiéndose a culminar el local de la biblioteca, lo cual no evitó que las obras se paralizarán en junio de ese mismo año. En julio se anunció que España financiaría la construcción de la Biblioteca mediante un crédito de 8 millones de dólares ("ESPAÑA financiará," 2005)

\footnotetext{
“Una visita del Presidente Toledo a la construcción selló la suerte de la nueva sede de la Biblioteca Nacional. Eran principios del 2005 (...) Los obreros se metieron a Toledo al bolsillo al recibirlo entre vítores y aplausos. El mandatario, además, descubrió un paisano suyo entre ellos, y ahí se definió todo. (“CÓMO MUDAR," 2006)
}

La inauguración generó una amplia cobertura de los medios, con extensas notas entre las que destacan las infografías de El Comercio ("LAS BONDADES," 2006, p. c5). Los columnistas 
y editorialistas celebraron la noticia desde antes de la inauguración y establecían analogías relativas al destino de la Biblioteca y el país, en La República opinaban: "la construcción inconclusa de la Biblioteca Nacional representó, en un país como el nuestro, cubierto de espléndidas ruinas del pasado, una especie perversa entre esos restos: el testimonio de un porvenir arruinado antes de llegar a ser" (OQUENDO, 2006)

Los informes de El Comercio de marzo del 2006 sobre la mudanza de los libros a la nueva sede daban cuenta del celo y cuidado con que los bibliotecarios asumían la labor: “Unos 250 estudiantes y profesionales de bibliotecología tuvieron la noble labor, y no menos titánica tarea, de limpiar cada libro que llegaba a sus manos utilizando una fina escobilla” ("LA BIBLIOTECA Nacional cambia de casa," 2006, p. a18)

\subsubsection{Devolución de libros por parte de Chile a la Biblioteca Nacional (2007)}

La noticia de devolución de libros por parte de Chile a la BNP generó la mayor cobertura de medios, incluso en diarios que habitualmente no realizan seguimiento a las actividades de la Biblioteca como Peru21, Trome y El Popular.

La devolución de libros superó el número de notas generadas por la inauguración de la nueva sede de la BNP. La razón se encuentra en los sentimientos que genera aún en nuestros días lo ocurrido en la guerra con Chile y el saqueo que sufrió el Perú como consecuencia de la invasión de territorio peruano por las tropas chilenas.

Los encabezados fueron: "Libros saqueados", "Libros robados", "Libros cautivos", "Chile devuelve parte del saqueo”, “¿Aún hay más libros saqueados en Chile?”, “Libros de la guerra”, "El gesto vale pero se espera más". "Rotos devuelven libros robados" (“ROTOS," 2007) La devolución de 3,778 libros fue considerada insuficiente por parte de la intelectualidad peruana que declaraba sobre lo que faltaba devolver. (CARLín, 2007, p. 16-17)

\subsubsection{Trafican con libros de Biblioteca Nacional (2009)}

“¿Habrá gente de la BNP involucrada en el tráfico?” Es la pregunta que se hace EI Comercio en primera plana, como tema del día, en campaña contra los traficantes del patrimonio nacional. (“TRAFICAN," 2009, p. a1)

Un coleccionista recibe la visita de un vendedor de antigüedades que le ofrece 4 libros cuya procedencia inequívoca es de la BNP. Las evidencias son contundentes, de uno de los ejemplares los vendedores ni siquiera se molestaron en retirar la etiqueta con el código de barras de la BNP; otro de los ejemplares figura en la Res. Dir. 217-2006-BNP que lo declara Patrimonio Cultural de la Nación y, finalmente, "De hecho, el libro de Daniel Concina ni siquiera 
figuraba en el banco de datos, según funcionarios de la BNP que rehusaron dar una declaración oficial. La búsqueda fue inútil" (HIDALGO, 2009, p. a2)

El 27 de enero se recogen las reacciones de la denuncia y se pide identificar a los autores de robo de libros de la biblioteca. La BNP informa que ha interpuesto denuncia policial y facilita la actuación de la fiscalía. Se entrevista a historiadores que condenan el hecho y solicitan una depuración de personal y que se mejore el sueldo que perciben. El Congreso de la República informó haber solicitado a la BNP dar cuenta del estado actual del caso y de las acciones tomadas para identificar a los responsables administrativos. ("PIDEN IDENTIFICAR," 2009, p. a8)

El Comercio del 12 de agosto publicó a página completa "Pérdidas de nuestra historia: continúan desapareciendo documentos valiosos", denuncia la inexistencia de rastros del grabado de un libro de 1684; se trata de la imagen de Nicolás Ayllón, el primer retrato impreso de un indígena de esa época. Se presentan testimonios de historiadores que aseguran haber consultado el libro en el que figuraba dicho grabado. Se consigna la declaración de la Directora de Servicios Bibliotecarios Especializados quien manifiesta que en su registro realizado el 2005 se da cuenta de dos grabados y ninguno es de Nicolás Ayllón. El Comercio, dice la nota, tuvo acceso a un antiguo microfilme tomado del libro de la BNP en el que aparece el grabado. (GALARZA, 2009, p. a2)

El manejo de medios para contrarrestar denuncias perjudiciales a la imagen de los órganos de gobierno se evidenció el 13 de agosto del 2009 cuando El Comercio y El Peruano publicaron notas opuestas sobre la denuncia presentada el día anterior.

El Peruano, diario oficial, recoge la versión del Director de la BNP, Hugo Neira, quien descartó la desaparición de documentos valiosos de sus bóvedas y cajas fuertes, espera una rectificación, "pero seguro a nosotros no nos van a dar dos páginas". Expresó que este tipo de informaciones genera desconfianza entre la población en cuanto al accionar de la BNP en la protección de documentos históricos y libros valiosos guardados durante años en sus bóvedas. (“DESCARTAN pérdida," 2009, p. 29)

Simultáneamente, El Comercio publica una nueva consulta a historiadores que confirman haber visto el grabado de Nicolás Ayllón en la BNP. Juan Carlos Estenssoro dice: "Yo conozco los dos ejemplares que hay en la Biblioteca Nacional de Madrid, uno tiene una anotación manuscrita de la censura inquisitorial y el otro tiene el sello de la Biblioteca Real, y ninguna de esas marcas está en el microfilme que le he entregado a El Comercio" (TRIVELLI, 2009, p. a9)

\subsubsection{Biblioteca Nacional cierra por robos (2011)}


La mayor campaña desarrollada en medios de comunicación masiva, teniendo como tema la BNP, es la que corresponde al año 2011. Se publicaron 84 notas, de las cuales 2 fueron editoriales, 5 informes a página completa y 3 portadas de diario.

Entre otros encabezados se leía: "Centro neurálgico de la cultura es una coladera", "Roban tesoros antiguos en Biblioteca Nacional", "Situación crítica", "Desaparecen pergaminos, microfilms y escritos de cronistas del siglo XVI", "Se perdieron originales de Arguedas", "Negligencia en seguridad de la BNP", "Mafias que de manera sistemática vienen sustrayendo los libros más valiosos".

En conferencia de prensa del 24 de febrero el Director de la Biblioteca, Ramón Mujica, anunció el cierre temporal para realizar un inventario general. "La pérdida de libros es un problema endémico que hemos heredado", aseveró. En la misma reunión, Hugo Neira recordó que en su gestión se ubicaron libros valiosos entre los denominados "de descarte", lo cual insinuó una modalidad interna de robo. (“CERRADO por inventario," 2011, p. 31)

El mismo día, en declaraciones para El Comercio, que le recordaba la denuncia de robo de libros de agosto del 2009, Neira decía sobre la investigación interna: “Nunca sirvió porque las comisiones investigadoras no trabajaron. Nadie quería acusar a sus compañeros". ("EL COMERCIO denunció," 2011)

Los medios difundieron datos que corresponderían al número de libros desaparecidos, siendo notoria la diferencia entre cifras proporcionadas en diversas notas conforme transcurría el tiempo y se obtenía información del inventario realizado.

El Comercio informaba el 25 de febrero: "Robaron al menos 663 libros", "Figuran en el catálogo electrónico pero no se encuentran en los depósitos" (..) "Yo mismo, que soy investigador, he buscado libros muy valiosos que consulté hace tres años, pero ya no están". (RAMÓN, 2011)

Ramón Mujica, en marzo del 2011, ante la Comisión de Educación del Congreso, detalló que dispuso la realización de una auditoría interna como producto del hallazgo de 113 carpetas que contenían 250 cartas dirigidas al mariscal Andrés Avelino Cáceres en los depósitos de basura de la sede bibliotecaria. Anotó como lo más condenable, el faltante de 544 documentos de la colección Porras Barrenechea y 28 de la colección Manuel Cisneros Sánchez, aparte de más de mil libros faltantes en las diferentes colecciones de la BNP. ("TRAS los libros," 2011)

El 23 de julio, El Comercio y La República informan, de acuerdo con el primer inventario, el robo de 932 libros de la BNP (“ROBO en la BNP," 2011) (“ROBAN 932," 2011)

El Comercio del 28 de agosto publica declaraciones de Ramón Mujica estableciendo que lo robado eran dos mil libros y manuscritos valiosos. Un subtítulo llama la atención: "Para el actual director, Ramón Mujica, ladrones laboran en la biblioteca"; se lee además: "hay una red 
criminal aquí dentro que está depredando los fondos antiguos", "Los robos vienen desde hace 20 años. Hay personal antiguo y nuevo implicado pero nadie habla por temor", "Al ser nombrados, no se les puede despedir. Duermo con el enemigo -insiste Mujica-." (SALAZAR, 2011, p. a12)

No es difícil imaginar el impacto de las declaraciones del director de la BNP en el personal y el clima laboral generado al interior de la Biblioteca. Una nota en el diario La Primera muestra la desproporcionalidad existente al recoger, de manera solitaria, la versión de los trabajadores de la BNP, frente al gran número de notas que recogen declaraciones del director de la Biblioteca. "Mujica ha asumido como irrebatible su hipótesis de que en la Biblioteca funciona un grupo delictivo que ha estado saqueando los archivos más valiosos." (WIENER, 2011)

Durante setiembre del 2011 los diarios: La Primera, La República y Peru21, consignaron Ios encabezados: "Ocultaron saqueo de Biblioteca Nacional: El director de la Biblioteca Nacional, Ramón Mujica, denunció que su propio personal le ocultó la desaparición de documentos valiosos, entre ellos miles de cartas y documentos enviados al mariscal Andrés Avelino Cáceres". "Denuncian que habría organización criminal dentro de la Biblioteca Nacional". "Mafia operaría en la Biblioteca Nacional: El director de esta entidad considera que una banda organizada está tras el robo de 932 libros y otros documentos, ocurrido en julio".

Después que un grupo de "recalcitrantes aguafiestas" (sic) intentara boicotear la cena de fin de año en la Biblioteca, Mujica declaró: "Uno tiene que ser justo. No puedes hacer acusaciones falsas, hay muchas honras de por medio". "Queremos dejar atrás esta etapa dolorosa de las denuncias -que continuaremos haciendo- y lanzar este año un agresivo plan cultural para la biblioteca". (PLANAS, 2012, p. c2)

Con respecto a los resultados del inventario, entre febrero y agosto del 2011 se inventarió 159,895 títulos con 321,703 volúmenes. "Poco, pues se estima que la biblioteca alberga 7 millones de libros y documentos y estos aún no tienen un inventario fidedigno." (SALAZAR, 2011) En enero del 2012 Ramón Mujica promete: "Por falta de presupuesto, los directores anteriores solo lograron hacer inventarios parciales. Nuestro objetivo es inventariar todos los fondos bibliográficos". (PLANAS, 2012, p. c2)

Finalmente, de lo publicado sobre la denuncia de robo de libros en la BNP, son elocuentes el título y los primeros párrafos del artículo de Eduardo Lores: "Nos están robando":

\footnotetext{
"A nadie le gusta que le roben, y esos libros y documentos que han desaparecido de la Biblioteca Nacional y del Archivo general de la Nación les pertenecen a todos los peruanos. Son como Machu Picchu, las Líneas de Nazca, la estela de Chavín, el Palacio de Torre Tagle, etc." (LORES, 2011, p. a3)
} 


\section{Análisis}

El análisis cualitativo de la muestra aborda la dimensión retórica del discurso en informaciones referidas a la BNP que permiten identificar las orientaciones que configuran las percepciones con respecto a la Biblioteca. Se trata de responder las siguientes interrogantes: ¿Cómo puede ser comprendida e interpretada la información difundida acerca de la BNP? ¿Qué sentido tiene el discurso, cuál es el trasfondo discursivo?

\subsection{Creencias culturales expresadas en los titulares de noticias relacionadas a la Biblioteca Nacional del Perú}

La BNP ha aparecido como "tema" en los medios impresos asociado al problema de abandono de la cultura; en años recientes el tema BNP se asocia al robo de libros y la necesidad de protección del patrimonio documental de la nación.

El "tema" conlleva siempre un elemento conflictivo, es decir, el elemento problemático es el que hace que los medios de comunicación de masas publiquen noticias exponiéndolo al ámbito de lo público.

Las creencias culturales se exploran mediante el registro de los términos expresados en los titulares de noticias relacionadas a la Biblioteca Nacional del Perú y sus significados implícitos en el conjunto de encabezados de notas periodísticas relativas a la BNP, a fin de establecer un conjunto de asociaciones fuertes delimitadas por la reiteración.

Las creencias culturales asociadas a la BNP, difundidas reiteradamente por los medios de comunicación, corresponden a las nociones de abandono, peligro permanente y enfermedad crónica. La Biblioteca, al igual que otras instituciones públicas peruanas, se ha instalado en el sistema de creencias como un ente enfermo, dependiente e indefenso. 


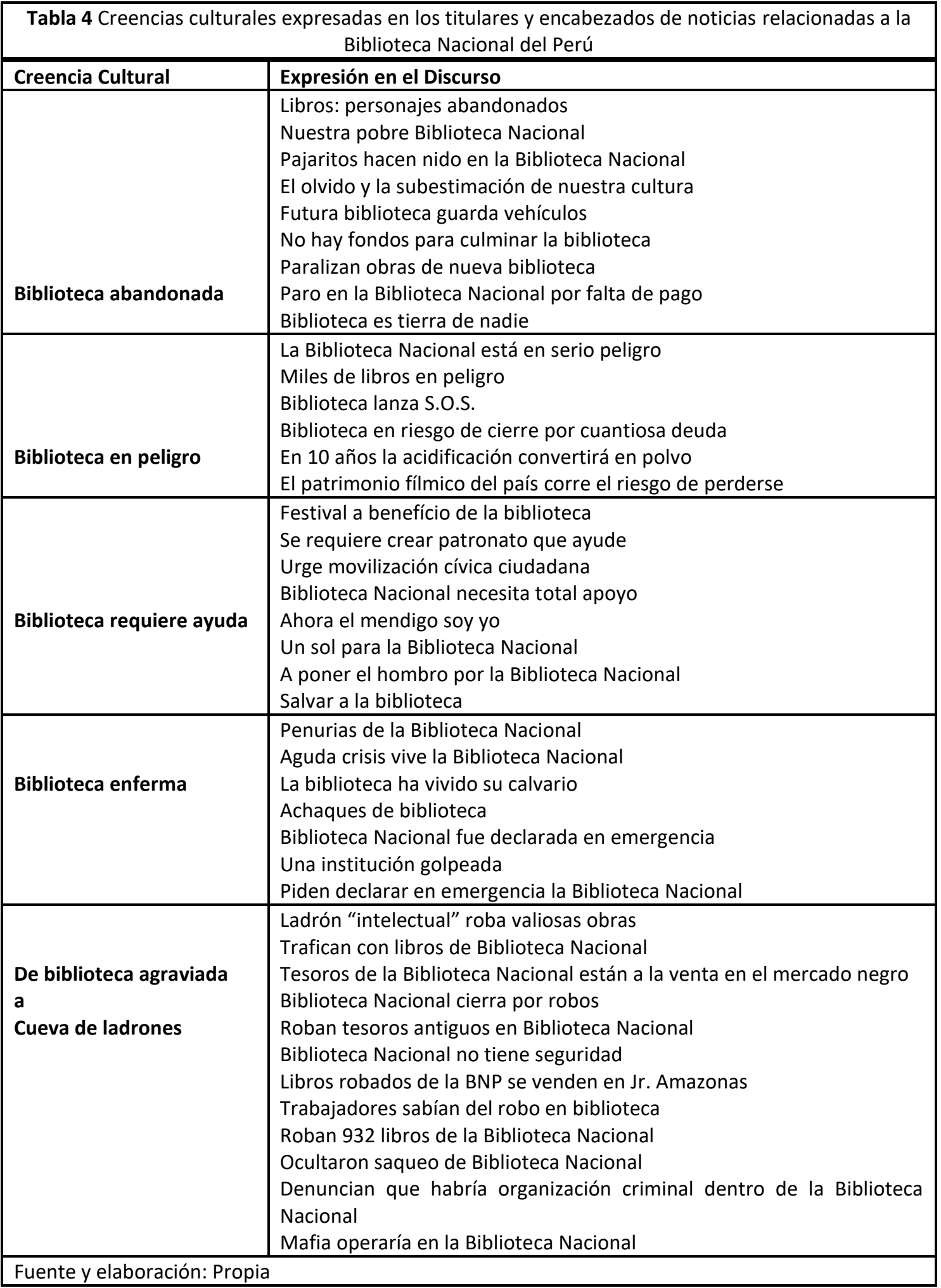

\section{2 ¿Qué tan cercano o familiar es el "tema" de la Biblioteca Nacional?}

La experiencia personal de la mayoría de los usuarios en el uso de la Biblioteca es reducida e intermediada, menor es el número de usuarios que experimenta el contacto con documentos históricos considerados patrimonio de la nación. Entonces, la realidad de la mayoría de la población es de desconocimiento y de escaso contacto o lejanía con la BNP, por 
lo que requiere que los medios le informen y orienten. Se trata de un público abierto y casi sin filtros para tratar el "tema" de la Biblioteca. "Cuanto menor es la implicación mayor es el efecto que produce el mensaje del medio en el público". (RODRÍGUEZ, 2004, p. 32)

Pardo (2013, p. 99-100) explica que cuando se explora el tema de los titulares o las portadas de los diarios, se reconoce cómo sintetizan los acontecimientos que la noticia se propone representar, jerarquizando y orientando la manera como acceder a ella. Los titulares condensan y definen la controversia, planteando de manera sistemática la totalidad discursiva, define y orienta temas e ideas. Como ejemplo, titulares del 2013 y 2014: "Un experto en ángeles y santos persigue a ladrones de libros: ¿Es un bibliotecario uno de los últimos combatientes contra la corrupción?” (HIDALGO, 2013). “Ramón Mujica: Patrono de la Cultura” (DE PAZ, 2014). "Ramón Mujica: cazador libresco: La intensa lucha del director de la BNP por recuperar el patrimonio bibliográfico" (“RAMÓN MUJICA," 2014)

De acuerdo con Cervantes $(1996,63)$ para seleccionar variables pertinentes y relevantes sobre la construcción primaria del acontecer se debe considerar, entre otros elementos: la procedencia de las solicitudes, si proviene de fuera o dentro del medio. La consideración de la procedencia de dentro es significativamente más efectiva. Durante los periodos en la dirección de la BNP correspondientes a Sinesio López y Hugo Neira, ambos eran columnistas de opinión en el diario La República. Si se emplean los buscadores de las páginas web de los diarios La República, El Comercio y otros similares, encontrarán mayor número de ocurrencias a búsquedas referidas a la BNP buscando: "Sinesio López" y "Hugo Neira" que buscando por "Biblioteca Nacional del Perú".

Las notas de prensa institucionales es lo más recurrente en los tiempos que corren, las organizaciones cuentan con áreas de prensa que difunden la noticia empleando el lenguaje periodístico, facilitan la labor de los medios que muchas veces sólo tienen que "voltear" la noticia. Lo llamativo del caso es que la propia BNP generó notas de prensa en la cual su imagen es afectada de forma negativa.

\subsection{Realidades vigentes y tradiciones heredadas}

Se ha observado en el estudio de las campañas periodísticas el uso recurrente del recurso de la entrevista a expertos en la Biblioteca Nacional. La entrevista, según Cervantes (1996, 64-65) busca dar objetividad en cuanto "dar voz" a las partes en conflicto salvaguarda el canon de la "neutralidad". Se trata de un ritual de la producción noticiosa, pero sobre la temática previamente impuesta. En el caso de la Biblioteca encontramos entrevistas a directores anteriores y actuales que plantean los temas prioritarios sobre los que debemos pensar respecto de los problemas de la Biblioteca. 
En la práctica, los periodistas hacen uso preferente de los archivos periodísticos para elaborar su nota informativa o de opinión, se nutren de enunciados previamente construidos y reproducen la tradición heredada, por eso el esquema cognitivo preexistente condiciona a la nueva información o la nueva situación, siendo muy difícil para alguien no familiarizado con temas cerrados como la organización bibliotecaria, plantear modificaciones significativas al conocimiento ya establecido. Las realidades vigentes y las tradiciones heredadas, en una dialéctica incesante. (CHILLÓN, 1998, p. 96)

a) Enfermedad crónica. La creencia de una Biblioteca enferma nos remite a conceptos de indefensión, de no poder superar las dificultades basado en sus propios recursos, de no poder superar una enfermedad sin ayuda exterior, es decir, de dependencia o dominación externa. La BNP ha sido declarada en emergencia más de una vez, intervenida y reorganizada, ha cambiado de personal casi completamente en distintos periodos y renovada su infraestructura, más sus males parecen incurables. Cada nueva crisis de un organismo enfermo como el de la Biblioteca convoca declaraciones de solidaridad y solicitudes de apoyo.

b) El recurso del miedo. El miedo a una pérdida potencial, a un nuevo incendio, a la lenta pero inexorable destrucción por malas condiciones de conservación, o la imperdonable negligencia por parte de los encargados de preservar la memoria nacional. El miedo es movilizador, expresa las urgencias con dramatismo e impone agendas. A veces las cosas se presentan tan mal en la biblioteca que nos es recordada como el símbolo de que la nación peruana puede transitar de nuevo por una tragedia, como el saqueo de documentos o la reducción a cenizas del patrimonio bibliográfico nacional.

c) La corrupción. Una nueva etapa de representación social parece haberse instaurado a raíz de la campaña mediática del año 2011 con sus antecedentes del año 2009, referida a los robos de libros en la BNP. La Biblioteca pasó de desprotegida y agraviada por malos elementos a convertirse en una cueva de ladrones.

La corrupción es uno de los peores males del país. La corrupción se ha extendido tanto que ha llegado a contaminar a la mayoría de las instituciones públicas. Cuando se destapan escándalos de corrupción en organismos públicos se habla de mafias enquistadas que han asumido el control de las organizaciones y actúan con impunidad.

\section{d) Historia, tradición, imaginario}

En la memoria social, es decir, en las creencias que poseemos en común con otros miembros del mismo grupo o cultura, la labor cultural de las bibliotecas se asocia a la sacrificada labor de reconstrucción realizada por Ricardo Palma y Jorge Basadre.

Palma y Basadre son considerados héroes culturales que asumieron con éxito el reto que se les presentaba como casi imposible: rescatar la memoria de la nación de los desastres 
que significaron la guerra con Chile y el incendio que consumiera la BNP. Desde entonces la labor de los bibliotecarios se encuentra signada por el sacrificio asociado a la tarea impuesta por la patria, de compromiso ineludible con la sociedad.

Para la mayoría de la población, la misión social, el contrato social de la biblioteca y los bibliotecarios, no es el de agente cultural que orienta, organiza y facilita información. Su función principal, es la de rescate y custodia del patrimonio bibliográfico de todos los peruanos; como custodio, debe ser esencialmente honrado.

\section{Conclusiones}

Entre los años 1945 y 2013 se han producido 13 campañas periodísticas que tienen como tema a la Biblioteca Nacional del Perú. La campaña "Biblioteca Nacional cierra por robos" (2011) ha generado mayor cobertura en medios por cantidad de noticias, columnas de opinión, editoriales generadas y permanencia en los medios.

A partir de la campaña del año 2011: "Biblioteca Nacional cierra por robos", la BNP ha pasado de ser representada como "agraviada" a ser observada como "cueva de ladrones".

Las notas de campañas periodísticas muestran el uso recurrente de entrevistas a expertos en la BNP: directivos de la institución y exdirectores, que plantean los temas prioritarios sobre los que debemos pensar respecto de los problemas de la Biblioteca.

Existe una cultura del secretismo en la Biblioteca. La experiencia personal de la mayoría de los usuarios en el uso de la Biblioteca es reducida e intermediada. Los no usuarios, al tratarse de un público abierto, requiere que los medios le informen y orienten sobre lo que ocurre en la Biblioteca.

Las notas informativas o de opinión sobre la BNP y su realidad vigente se nutren de enunciados previamente construidos y reproducen tradiciones heredadas. Las creencias culturales asociadas a la BNP la representan como abandonada, en peligro, requerida de ayuda y con enfermedad crónica.

\section{Referencias}

ALPISTE, Martín. Cierre anunciado: Biblioteca Nacional en reorganización. El Peruano. Lima, 3 feb. 1993. Revista suplemento cultural, p. 8-9.

ARRUNÁTEGUI, Carolina. Ideología y prensa escrita en el Perú: el caso Bagua. Lexis, v. 34, n. 2, p. 353-368, 2010.

BASADRE, Jorge. En la Biblioteca Nacional. Ante el problema de las "élites". Lima: P.L. Villanueva, 1968. 
BIBLIOTECA Nacional en peligro: Está rodeada de orates, mendigos, delincuentes y homosexuales. Correo, Lima, p. 1, 31 Ene. 1978.

BIBLIOTECA Nacional en riesgo de cierre por cuantiosa deuda: A Sedapal, Electrolima y CPT debe I/m 176,540. El Peruano, Lima, p. B10, 10 Ene. 1991.

BIBLIOTECA Nacional necesita total apoyo: Para que deje de ser una simple entidad pública y se convierta en centro de investigación de la realidad peruana. El Comercio, Lima, p. A8, 6 Feb. 1993.

BIBLIOTECA Nacional pide urgente ayuda. La República, Lima, p. 9, 13 Set. 1990.

BIBLIOTECA Nacional reabrirá sus puertas el primero de abril con mejoras inconclusas. EI Comercio, Lima, p. A12, 18 Mar. 1993.

BIBLIOTECA no puede comprar más libros: presupuesto mensual es de 54 mil soles. El Comercio, Lima, p. 1, 23 Ago. 1980.

CABINAS con acceso a Internet tendrá la Biblioteca Nacional: también tendrá una red de catálogos públicos automatizados. El Comercio, Lima, p. A17, 1 Ago. 1997.

CARLÍN, Ernesto. Biblioteca pródiga: Regresan al Perú libros perdidos de la Biblioteca Nacional durante ocupación chilena. El Peruano, Lima, p. 16-17, 7 Nov. 2007.

CASTILLO, Andrea. Nueva sede de Biblioteca Nacional: ¿El cuento de nunca acabar?: EI Comercio, Lima, p. A10, 1 Ene. 1994.

CASTRO, Patricia. La memoria en construcción: Obra pendiente Biblioteca Nacional piso a piso. El Comercio, Lima, p. C23. 19 Ene. 2003.

CENTROMín no entregó terreno a la Biblioteca Nacional. El Comercio, Lima, p. A6, 27 Dic. 1994.

CERRADO por inventario: Biblioteca Nacional no atenderá durante 90 días. El Peruano, Lima, p. 31, 25 Feb. 2011.

CERVANTES, Cecilia. Construcción primaria del acontecer y planeación de la cobertura informativa: Propuesta metodológica para su estudio. Comunicación y Sociedad, (v. 28, p. 4981, 1996.

CHILLÓN, Albert. El "giro lingüístico» y su incidencia en el estudio de la comunicación periodística. Anàlisi, v. 22, p. 63-98, 1998.

CISNEROS, Manuel. Por una Biblioteca Nacional operativa y segura: Dr. José Tamayo Herrera. EI Comercio, Lima, 27 Ene. 1991. El Dominical, p. 3.

CóMO mudar una biblioteca: Más de 3 millones de libros en camino al nuevo local de la Javier Prado. Caretas, (1915), pp. 40-43, 2006.

CÓRDOVA, Jorge. La biblioteca escolar en la bibliografía nacional. Lima: Ministerio de Educación. Dirección de Bibliotecas Escolares, 1982.

DE 7 millones asignados sólo 2 recibe Biblioteca Nacional. El Comercio, Lima, p. 7, 1 Ago. 1980. 
DE PAZ, Maribel. Ramón Mujica: Patrono de la Cultura. Caretas, (2360), 2014. Disponible en: http://www.caretas.com.pe/Main.asp?T=3082\&S=\&id=12\&idE=1181\&idSTo=0\&idA=69921\#.V $\underline{\text { Zs3-Pk3nOQ }}$

DE TOROS: Un gran éxito fue ayer el festival en beneficio de la Biblioteca Nacional. El Comercio, Lima, p. 5, 5 Mar. 1945.

DESCARTAN pérdida de libro en la Biblioteca Nacional: Aclaración, Director de BNP señala que nunca se tuvo texto con grabado de Ayllón. El Peruano, Lima, p. 29, 13 Ago. 2009.

DONE un sol y salve a la Biblioteca Nacional del Perú. La República, Lima, p. 26, 5 Set. 2003.

EL COMERCIO denunció hace dos años robo sistemático de libros: Sustraen documentos a vista y paciencia de todos. El Comercio, Lima, p. A3, 25 Feb. 2011.

EL LUJO debe dar dinero a la Biblioteca: Basadre propone un impuesto sobre artículos suntuarios. Correo, Lima, p. 1, 8 Feb. 1978.

EL PATRIMONIO fílmico del país corre el riesgo de perderse: Hay más de dos mil películas de nitrato en la Biblioteca Nacional. El Comercio, Lima, p. 1, 16 Feb, 2002.

ESCRIBANO, Pedro. Ahora el mendigo soy yo: Sinesio López lanza campaña de un sol para nueva sede de Biblioteca Nacional. La República, Lima, p. 20, 14 Ago. 2003.

ESPAÑA financiará construcción de Biblioteca Nacional del Perú. Peru21. Lima, 28 Jul. 2005. Disponible en: http://archivo.peru21.pe/noticia/38694/espana-financiara-construccionbiblioteca-nacional-peru

ESTADO nunca entendió la verdadera función: según opiniones de exdirectores: Biblioteca Nacional. El Comercio, Lima, p. A9, 4 Nov. 1991.

ESTRADA. Alonso y HUAMÁN, Roxana. Posicionamiento de las bibliotecas universitarias peruanas en los medios de comunicación. Investigación bibliotecológica, v. 24, n. 51, p. 13-41, 2010.

ETO, G. Bagua: un conflicto en primera plana. 2010. Tesis (Maestría) - Pontificia Universidad Católica del Perú. Escuela de Posgrado. Comunicaciones. Disponible en: http://tesis.pucp.edu.pe/repositorio/handle/123456789/1022

FALTA presupuesto para tres pisos de nueva sede de Biblioteca Nacional. El Comercio, Lima, p. A12, 15 May. 1996.

FESTIVAL Taurino en beneficio de la Biblioteca Nacional. Boletín de la Biblioteca Nacional del Perú, v. 2, n. 7, p. 283-291, 1945.

FLOR, Enrique. Nuevo local de la Biblioteca es utilizado como cochera: por falta de presupuesto las obras están paralizadas hace dos años. El Comercio, Lima, p. A21, 9 Jun. 1999.

GALARZA, Gonzalo. Pérdidas de nuestra historia: Continúan desapareciendo documentos valiosos. El Comercio, Lima, p. A2, 12 Ago. 2009. 
GARCIA, Alberto. Obras de la Biblioteca Nacional llegarán a un 60\% para junio. La República. Lima, 2 Feb, 2005. Disponible en: https://larepublica.pe/sociedad/315383-obras-de-labiblioteca-nacional-Ilegaran-a-un-60-para-junio

HACE cuatro meses están paralizadas las obras de nuevo local de Biblioteca. El Comercio, Lima, p. A10, 17 Jun. 1997.

HAY evidente falta de seguridad: Biblioteca Nacional. El Comercio, Lima, p. A7, 8 Mar. 1993.

HIDALGO, David. Tesoros de la Biblioteca Nacional están a la venta en el mercado negro, incluso por 'delivery': Libros de los siglos XVI y XVIII pertenecen a fondos para investigadores. Una de las joyas rescatadas figura como Patrimonio Cultural de la Nación. El Comercio, Lima, p. A2, 26 Ene. 2009.

HIDALGO, David. Un experto en ángeles y santos persigue a ladrones de libros: ¿Es un bibliotecario uno de los últimos combatientes contra la corrupción? Etiqueta negra, n. 113, 2013. Disponible en: http://etiquetanegra.com.pe/articulos/un-experto-en-angeles-y-santospersigue-a-ladrones-de-libros

LA BIBLIOTECA Nacional cambia de casa: Empezó la mudanza. El Comercio, Lima, p. A18, 12 Mar. 2006.

LA BIBLIOTECA Nacional está en serio peligro. La cercan orates, mendigos, delincuentes y homosexuales. Correo, Lima, p. 12-13, 31 Ene. 1978.

LA UNI tiene una cuenta por cobrar de 560 mil soles: La Biblioteca Nacional en el olvido. EI Comercio, Lima, p. A9, 5 Set. 1998.

LAS BONDADES de la nueva sede: En San Borja: Instalaciones. Servicios. El Comercio, Lima, p. C5, 26 Mar. 2006.

MACASSI, Sandro y SUBAUSTE, Enrique. Principales hallazgos del estudio sobre tratamiento informativo y gestión periodística en los conflictos medioambientales. Lima: Asociación Calandria, 2009.

MEF dará \$11,5 millones para concluir Biblioteca Nacional: Al cumplirse 181 años de su fundación, esa institución recibirá además un crédito de \$12 millones para equipar su local de San Borja. El Comercio, Lima, p. A23, 1 Set. 2002.

NO hay fondos para culminar la Biblioteca, afirma el presidente: Desilusión a la cultura. EI Comercio, Lima, p. A5, 10 Jun. 1999.

PARDO, Neyla. Cómo hacer análisis crítico del discurso: Una perspectiva latinoamericana. 2da edición. Bogotá: Universidad Nacional de Colombia, Instituto de Estudios en Comunicación y Cultura, 2013.

PERÚ es uno de los primeros en América Latina que publica su patrimonio bibliográfico nacional. El Comercio, Lima, p. 11, 29 Ago. 1979.

PIDEN identificar a autores de robo de libros de la biblioteca: El Comercio en campaña contra los traficantes del patrimonio nacional. El Comercio, Lima, p. A8, 27 Ene. 2009. 
PLANAS, Enrique. El hombre que creía en milagros: Ramón Mujica y la renovada Biblioteca Nacional: Relanzamiento. El Comercio, Lima, p. C2, 11 Ene. 2012.

¡QUÉ tiempos aquellos...!: Biblioteca Nacional. El Comercio, Lima, p. C2, 14 Mar. 1993.

RAMÓN Mujica: cazador libresco: La intensa lucha del director de la BNP por recuperar el patrimonio bibliográfico. Caretas, (2366), 2014. Disponible en: http://www.caretas.com.pe/Main.asp?T=3082\&S=\&id=12\&idE=1187\&idSTo=766\&idA=70423\# .VZs4FPk3nOQ

RAMÓN, Roxabel. Robo en la BNP: desaparecieron hasta libros grabados en pan de oro. EI Comercio. Lima, 25 Feb. 2011. Disponible en: http://elcomercio.pe/lima/sucesos/robo-bnpdesaparecieron-antiguos-libros-grabados-pan-oro-noticia-718872

REDUCEN partida presupuestal para la Biblioteca. El Comercio, Lima, p. A7, 16 Abr. 1993.

ROBAN 932 libros de la Biblioteca Nacional, según inventario. La República, Lima, p. 23, 23 Jul. 2011.

ROBO en la BNP: primer inventario reveló que 932 libros fueron sustraídos: El director de la Biblioteca Nacional, Ramón Mujica, le pidió al Estado declaratoria de emergencia. El Comercio. Lima, 23 Jul. 2011. Disponible en: http://elcomercio.pe/lima/sucesos/robo-bnp-primerinventario-revelo-que-932-libros-fueron-sustraidos-noticia-

943585? ref=flujo tags $252898 \& \mathrm{ft}=$ nota $9 \& \mathrm{e}=$ titulo

RODRÍGUEZ, Raquel. Los profesores universitarios como medios de comunicación: La AgendaSetting de los alumnos y profesores. 2000. Tesis (Doctoral). Universidad Complutense de Madrid. Facultad de Ciencias de la Información. Disponible en: https://eprints.ucm.es/5239/1/T24877.pdf

RODRÍGUEZ, Raquel. Teoría de la Agenda-Setting: aplicación a la enseñanza universitaria. Alicante: Observatorio Europeo de Tendencias Sociales, 2004. Disponible en: http://hdl.handle.net/10045/2297

RODRÍGUEZ, César A. Una biblioteca para un pueblo: En torno a una campaña. Correo, Lima, p. 10, 8 Feb. 1978.

ROTOS devuelven libros robados. El Popular. Lima, 5 Nov. 2007. Disponible en: https://www.elpopular.pe/actualidad-y-policiales/2007-11-05-rotos-devuelven-libros-robados

SALAZAR, Elisabeth. Dos mil libros y manuscritos valiosos han sido robados: La Biblioteca Nacional sigue en riesgo. El Comercio, Lima, p. A12, 28 Ago. 2011.

SOCIEDAD de Amigos de la Biblioteca Nacional. El Comercio, Lima, p. 2, 20 Set. 1979.

TRAFICAN con libros de Biblioteca Nacional. El Comercio, Lima, p. 1, 26 Ene. 2009.

TRAS los libros perdidos: Comisión del Congreso investigará robo de valores en Biblioteca Nacional. El Peruano, Lima, p. 30, 9 Mar. 2011.

TRIVELLI, Carlo. Grabado perdido sí fue visto en ejemplar de la Biblioteca Nacional. Un microfilme entregado a El Comercio prueba la desaparición. Lo confirman historiadores. EI Comercio, Lima, p. A9, 13 Ago. 2009. 
UN SOL para la biblioteca: Buenos días. El Comercio, Lima, p. 1, 28 Ago. 2003.

UNA COMISIÓN revalorizará bibliotecas. El Comercio. Lima, 14 Oct. 1991.

25 MILLONES al patronato: Financieras a Biblioteca. Correo, Lima, p. 1, 10 Feb. 1978.

WIENER, Raúl. (2011, Setiembre 3). Rara desaparición de libros en la Biblioteca Nacional: El director Ramón Mujica Pinilla afirma que existe mafia de trabajadores de alta especialidad de esa institución, pero hay gato encerrado. La Primera. Lima, 3 Set. 2011. Disponible en: http://www.diariolaprimeraperu.com/online/politica/rara-desaparicion-de-libros-en-labiblioteca-nacional 93839.html

YA HAY treinta millones para Biblioteca Nacional: Se elaborará reglamento para concretar aporte de financieras. Correo, Lima, p. 7, 15 Feb. 1978.

ZAPATA, Mariza. Hay una colección de improvisaciones: La Biblioteca Nacional. El Comercio, Lima, p. A9, 3 Nov. 1991. 